\title{
Roof structures. Comparisons between traditional roof structures and industrialized ones
}

\author{
Draghici Gabriela, Maican Ana-Maria, Rotaru Valentin
}

\begin{abstract}
Roofs with one or more slopes, represent an important part of a construction, having a double role: a role of resistance together with the entire constructive system and a protective role both for the other components of the constructive system and for the optimal unfolding of the various functions. The durability and the fulfillment of the mechanical requirements depend equally on the material used, design quality and execution quality. Industrialized roof structures can be a solution, under the current conditions, to meet these requirements. This article compares the traditional roof structures and the industrialized one.
\end{abstract}

Keywords - roof structure, durability, bending resistance

\section{INTRODUCTION}

Wood for construction is a material used since ancient times. However, being a natural material, its physical and mechanical properties have higher limits of use. Studying wood for construction, both macroscopically, in structure, and microscopically, at the cellular level, leads to solutions that improve performance. The study of wood will certainly take into account a number of parameters such as wood exploitation classes, characteristic resistances of natural wood, as well as other parameters.

Roofs can be flat or may have one or more slopes. Roofs with slopes are made with resistance structures called frameworks. The frameworks can be traditional or industrialized.

Manuscript received $12^{\text {th }}$ of August 2017

1. Draghici Gabriela - Ovidius University of Constanta, Bd. Mamaia nr. 124, 900356-Constanta, Romania (corresponding author phone: +40-241-619040; fax: +40-241-618372; e-mail: g.draghici@yahoo.com)

2. Eng Maican Ana-Maria - MA student, Ovidius University of Constanta, Bd. Mamaia nr. 124, 900356Constanta, Romania (e-mail: ana_maria1993@yahoo.com)

3. Eng. Rotaru Valentin - Daniel, Ph.D. candidate - Ovidius University of Constanta, Bd. Mamaia nr. 124, 900356-Constanta, Romania (e-mail: ing.valentin.rotaru@gmail.com) 


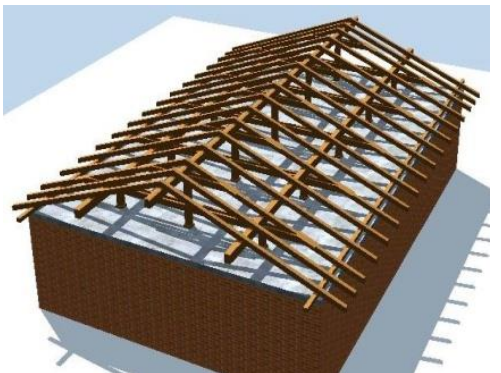

Fig. 1 Traditional roof(source - author)

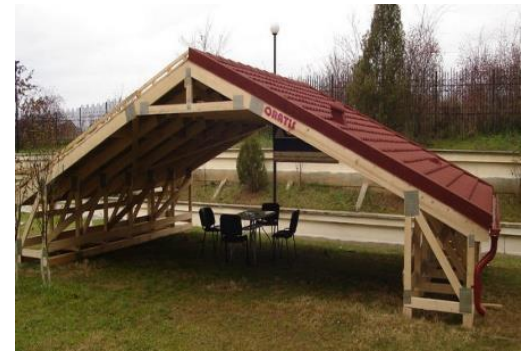

Fig. 2 Industrialized roof(source: [4])

\section{THE PRESENTATION OF CASE STUDY ON WOOD FRAMING}

Wood framing represents the structure that supports the roof.

Traditional roof structures have been used since ancient times and developed so far.

Traditional framing is composed by top plate, prop, ridge, roof ridge, roof valley (where applicable), rafter, roof sheathing. On this structure are placed the layers of the roof cover. As can be seen in Fig. 1, the free space witch can be used for an attic or for a mansard roof is limited to ensure the conditions for strength and rigidity.

It is considered a roof structure with an approximate area of 100,00 square meters. The cross-sectional distance of the building is 8,00 meters and the length of the building is 12,00 meters.

For pre-dimensioning step, the following are proposed, according to Fig.3. Roof Structure Plan.

- Roof sheating is considered to have a width $\mathrm{b}=250 \mathrm{~mm}$ and a thicknessh $=$ $25 \mathrm{~mm}$, placed on the rafters at an inter-axial distance between raftersd $1=800 \mathrm{~mm}$;

- The rafters are considered to be $b=100 \mathrm{~mm}$ in width, the height $\mathrm{h}=120 \mathrm{~mm}$ and the lenght $1=2000 \mathrm{~mm}$, disposed at an interax distance $\mathrm{d}_{1}=800 \mathrm{~mm}$;

- The roof ridge is considered to have the width $\mathrm{b}=150 \mathrm{~mm}$ and the height $\mathrm{h}=$ $200 \mathrm{~mm}$;

- The vertical elements - the props- are proposed with the cross-section dimension $150 \times 150 \mathrm{~mm}^{2}$ and the height $\mathrm{h}=1400 \mathrm{~mm}$.

The sizing and verification calculations are performed using Limit State Method - ultimate limit state - for sizing and serviceability limit state - for deformation limits according to Eurocod 5 [ 1] si NP005- 03 [2].

For calculating the roof structure in both solutions traditional or industrialized were considered dead loads, environmental loads and live loads. weight.

Dead loads refer to the roof structure's self weight and the roof cover's self

Environmental loads refer to wind loads and snow loads,

Live loads are reprezented by a concentrated force that comes from the weight of a man of about $100 \mathrm{~kg}$ who performs roof repairs. 
The followinf charging hypotheses were considered

- Hypothesis I: dead loads + snow loads;

- Hypothesis II: dead loads + wind loads + half of snow loads

- Hypothesis III: dead loads + concetrated force that reprezents live loads

The calculation formula used for each element subjected to bending is:

$$
\mathbf{R}_{\text {înc }}^{\mathbf{c}}=\mathbf{m}_{\mathbf{u i}} \cdot \mathbf{m}_{\mathbf{d i}} \cdot \frac{\mathbf{R}_{\mathbf{i}}}{\gamma_{\mathrm{i}}}(\mathbf{1}), \text { formula according to [2], where : }
$$

- $\mathbf{m}_{\mathbf{u i}}$ is the coefficient of working conditions which introduces the wood's equilibrium humidity, at different stresses, depending on exploitation classes of the building elements to be designed;

$-\mathbf{m}_{\mathbf{d i}}$ is the working conditions factor that introduces the wood's equilibrium humidity, defined on the basis of the microclimate conditions in which the building elements being designed are exploited;

$-\mathbf{R}_{\mathbf{i}}$ is the characteristic resistance of different wood species;

$-\gamma_{\mathbf{i}}$ is the partial security coefficient defined by the type of stress

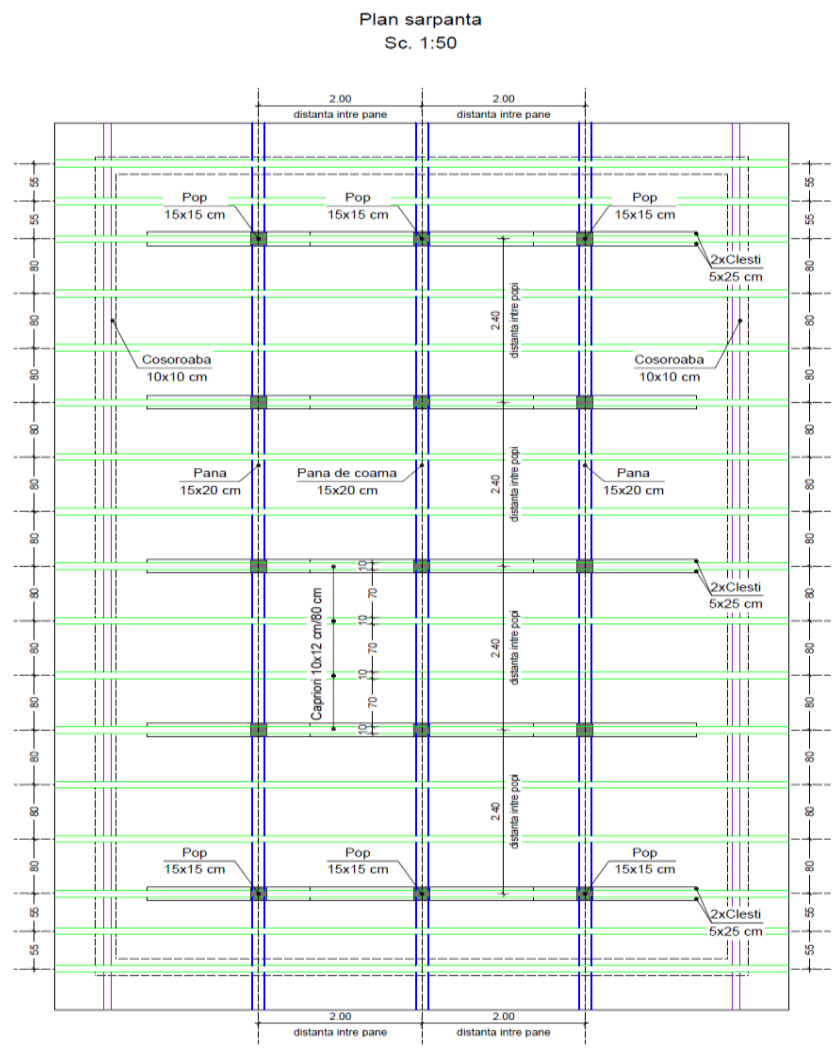

Fig. 3 Plan şarpantă (sursa - autor) 
82 Ovidius University Annals Series: Civil Engineering, Issue 19, 2017

Using the results established on the basis of formula (1), the bending moments were then calculated for each element subjected to the bending effort. It has been considered that all the elements (rafters, ridge) are simply supported.

The rafters are wooden beams arranged along the roof slope, being simple beams rested on the pane. For the end of the rafter that comes out of the console, the calculation scheme is beam-console

The ridge board represent vertical supports for rafters, so that the ramps are calculated by considering the horizontal displacement beam (with the same moments), the opening $d_{2}$ loaded with horizontally uniformly distributed vertical loads, or the sloping opening beam $1_{2}$, loaded with normal loads on the beam axis and evenly distributed on the beam length.

Ridge board are wooden beams arranged along the building. These are loaded with the rafter reactions, which are disposed at small distances, it is assumed that the load on the wedge is evenly distributed. The panels are considered to be simply leaning on props. The load on the ridge board is determined on the corresponding surface.

The formula for calculating the moment is:

$$
\mathbf{M}_{\mathbf{r}, \text { elem }}=\mathbf{R}_{\text {înc }}^{\mathbf{c}} \cdot \mathbf{W} \cdot \mathbf{m}_{\text {Tînc }} \text { (2) formula according to [2], where: }
$$

$-M_{r x, e l e m}, M_{r y, e l e m}$ are the bearing capacities of the static bending element in the direction of the two main inertia axes, determined according to the load and the computing opening of the elements;

$-\mathrm{R}_{\text {înc }}^{\mathrm{c}}$ is the calculation resistance of different wood species at bending, depending on the operating conditions of the building elements to which it relates;

$-\mathrm{W}_{\mathrm{x}}, \mathrm{W}_{\mathrm{y}}$ are the modulus of resistance for the most requested section of the element along the two main axes;

$\mathbf{m}_{\text {Tînc }}$ is the coefficient of wood treatment at static bending, which introduces the modification of the resistances of the wood at the request $i$, depending on the preservation methods, the dimensions of the parts and the class of the building exploitation

For props it was considered the static compression buckling scheme, for which the formula is:

$$
\mathbf{C}_{\mathbf{r}}=\mathbf{R}_{\mathbf{c I I}}^{\mathbf{c}} \cdot \mathbf{A}_{\mathbf{p o p}} \cdot \mathbf{m}_{\mathrm{Tc}} \cdot \boldsymbol{\varphi} \text { (3), formula according to [2 ], where: }
$$

$-\mathrm{C}_{\mathrm{r}}$ is the resilience capability of solid wood elements with a simple section required for axial compression parallel to the fibers;

$-\mathrm{R}_{\mathrm{cII}}^{\mathrm{c}}$ is the calculation resistance of solid wood at axial compression parallel to the fibers;

$-A_{\text {pop }}$ is the pop area;

$-\mathrm{m}_{\mathrm{Tc}}$ is the wood treatment coefficient;

$-\varphi$ is the buckling coefficient; 


\section{PRESENTATION OF DATA AND RESULTS}

The roof structure submitted to the case study was sized and verified in two ways:

- using the traditional structure roof for which the calculation is carried out in the sizing steps [1] and [2] and verification and for which the joints in the node are also treated at the building site; the roof sheating, the rafts, the ridge board and props have been dimensioned and verified;

- using a structural engineering software, software which includes all the conditions of strength and rigidity, but also the constructive knot-joining characteristics according to [1], [3] and [5];

- roof sheating, the rafts, the ridge board and props have been dimensioned and verified;

In the case of traditional roof structure, the actual bending moments are those shown in table no. 1 .

Table 1. The value of calculation moments using traditional methodes

\begin{tabular}{|l|c|c|c|}
\hline \multicolumn{1}{|c|}{ Element } & Dimensions & Effort & Values \\
\hline Roof sheathing & $25 \times 2,5(\mathrm{~cm})$ & Bending Stress & $\begin{array}{l}\mathrm{M}_{\text {efx,astereală }}=0,004 \mathrm{kN} \cdot \mathrm{m} \\
\mathrm{M}_{\text {efy,astereală }}=0,013 \mathrm{kN} \cdot \mathrm{m}\end{array}$ \\
\hline Rafter & $10 \times 12(\mathrm{~cm})$ & Bending Stress & $\mathrm{M}_{\text {ef,căprior }}=0,78 \mathrm{kN} \cdot \mathrm{m}$ \\
\hline Ridge board & $15 \times 20(\mathrm{~cm})$ & Bending Stress & $\begin{array}{c}\mathrm{M}_{\text {efx,pană }}=0 \\
\mathrm{M}_{\text {efy,pană }}=11,22 \mathrm{kN} \cdot \mathrm{m}\end{array}$ \\
\hline Prop & $15 \times 15(\mathrm{~cm})$ & Compressive Stress & $\mathrm{N}_{\text {ef }}=13,18 \mathrm{kN}$ \\
\hline
\end{tabular}

In the case of using structural engineering software, the actual bending moments are those shown in table no. 2 .

Table 2. The value of the calculation moments when using the structural engineering software

\begin{tabular}{|l|c|c|c|}
\hline \multicolumn{1}{|c|}{ Element } & Dimensions & Effort & Values \\
\hline Rafter & $4,8 \times 13,5(\mathrm{~cm})$ & Bending Stress & $\mathrm{M}_{\mathrm{ef}}=0,83 \mathrm{kN} \cdot \mathrm{m}$ \\
\hline Ceiling joist & $4,8 \times 13,5(\mathrm{~cm})$ & Bending Stress & $\mathrm{M}_{\mathrm{ef}}=0,59 \mathrm{kN} \cdot \mathrm{m}$ \\
\hline Prop & $4,8 \times 8,00(\mathrm{~cm})$ & Compressive Stress & $\mathrm{N}_{\mathrm{ef}}=26,35 \mathrm{kN}$ \\
\hline
\end{tabular}

\section{RESULTS AND SIGNIFICANCES}

It can be observed that in the case of industrialized roof structure, in which all the joining elements have structural role, the structural elements can take over higher loadings. The cross sections can be smaller than in traditional roof structure and it can be designed with larger openings of the buildings.

Also the sectioned elements can be treated and flameproof in the factory, thus increasing the strength of the roof and its durability. 


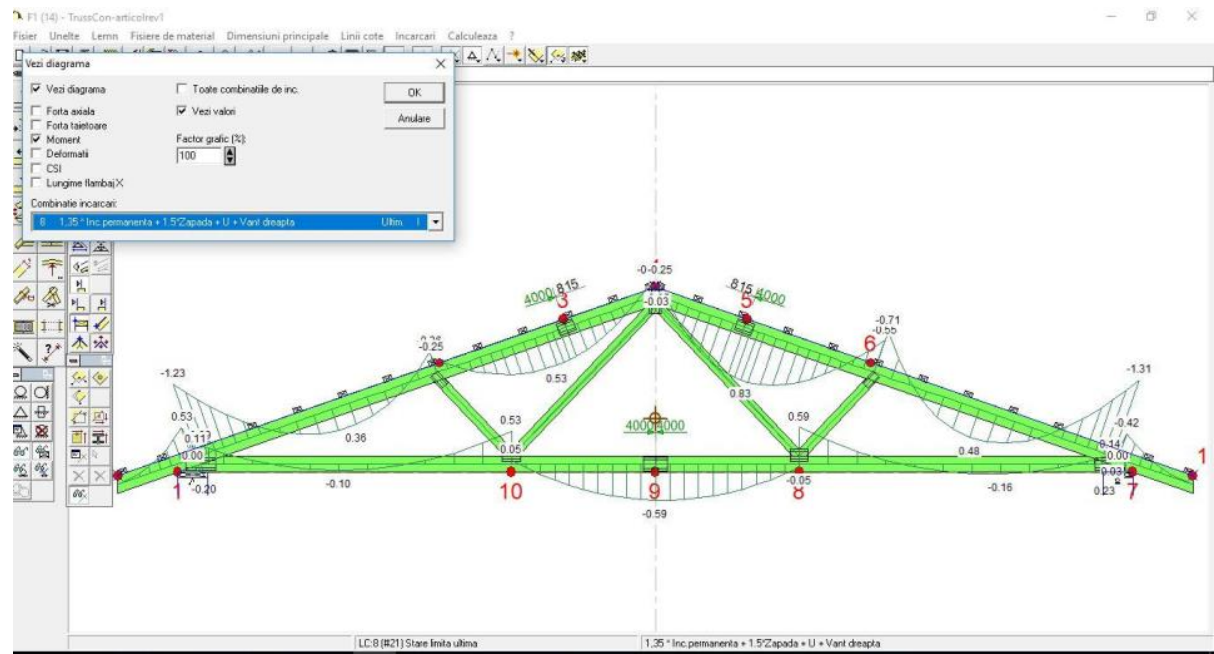

Fig. 4 The moment diagram using structural engineering software according to [4]

\section{CONCLUSIONS}

Since ancient times, traditional roof structure have evolved both in terms of the execution technology and design terms, but the great influence for creating a quality roof structure is the human factor.

Also, the control of the wood material on site is an important factor because it can't be done with the utmost precision to identify its actual humidity, necessary to fit some values according to [1], [2] and [5] in order to meet the requirements relating to mechanical properties; it is not possible to control precisely whether the wood to be put into operation has been or has not been properly treated against pests

In the case of traditional roof structure, material losses can not be eliminated, and this is one of the reasons why flame retardation is usually done for sliding subsystems and not for each element.

Compared to traditional roof structure, in the case of industrialized roof structures, the material undergoes the preparatory steps and is certified in terms of the values of the mechanical properties it has to perform. It is also possible to increase the usable space inside the roof due to the higher load bearing capacity of the roof structure.

Apparently, the cost of an industrialized shingle is higher, but by reducing the length of execution and, implicitly, labor, and by reducing material losses, the cost difference diminishes.

In one situation, namely in the case of monument constructions in the process of restoration and consolidation, the requirements of resistance, stability and durability will be met but with the preservation of the materials used during the construction and the observance of the execution technology during the respective period. 


\section{REFERENCES}

[1] ASTM 04.10 Wood D143-09 - Standard Test Methods for Small Clear Specimens of Timber

[2]. xxx, EN 14250: 2010 - Structuri din lemn. Cerinte privind produsele pentru elementele de structura prefabricate asamblate cu elemente de fixare cu placa metalica ambutisata

[3]. xxx, Eurocode EC5, ENV 1995-1-1994, Design of timber structures. Part 1.1:

General rules and rules for buildings

[4]. xxx, NP-005 - 03 - Standard on wood building design

[5]. xxx, SR EN 338:2010 - Lemn pentru construcţii. Clase de rezistenţă

[6]. http://www.mitek.ro 